
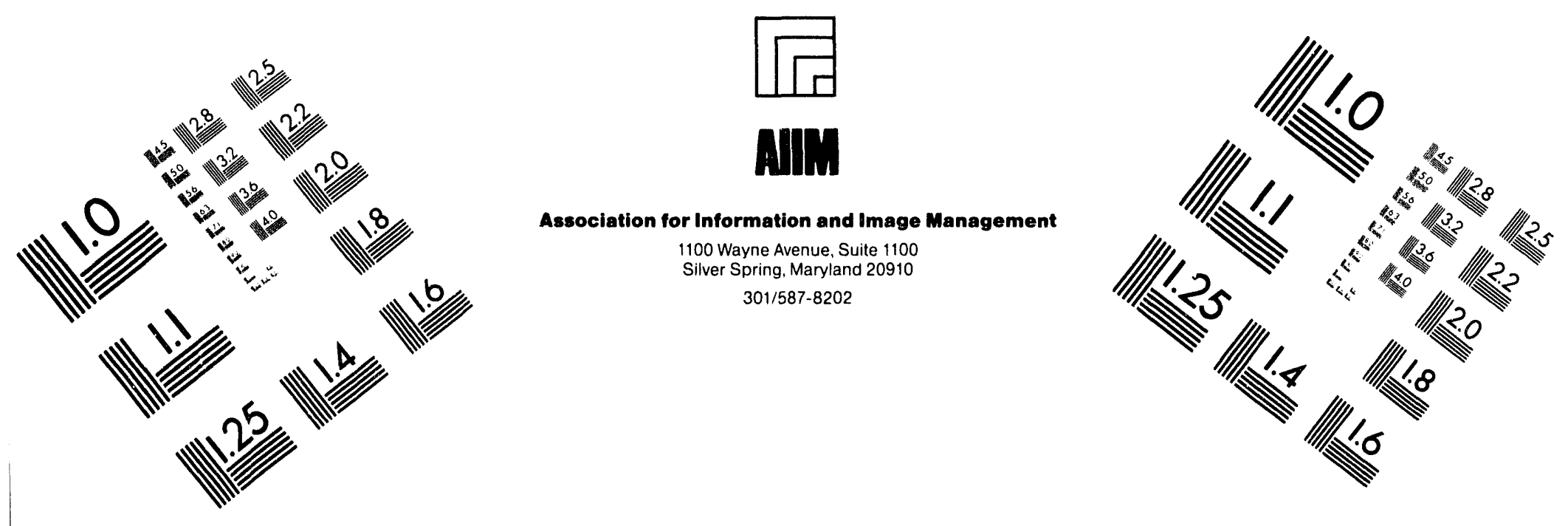

\title{
Centimeter
}

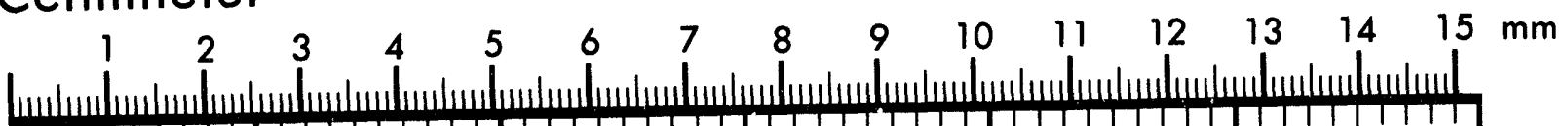

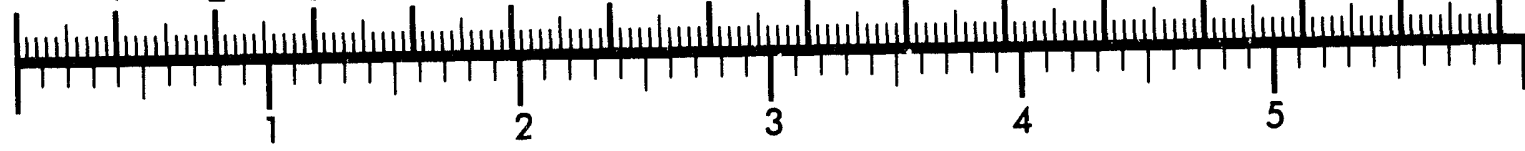
Inches
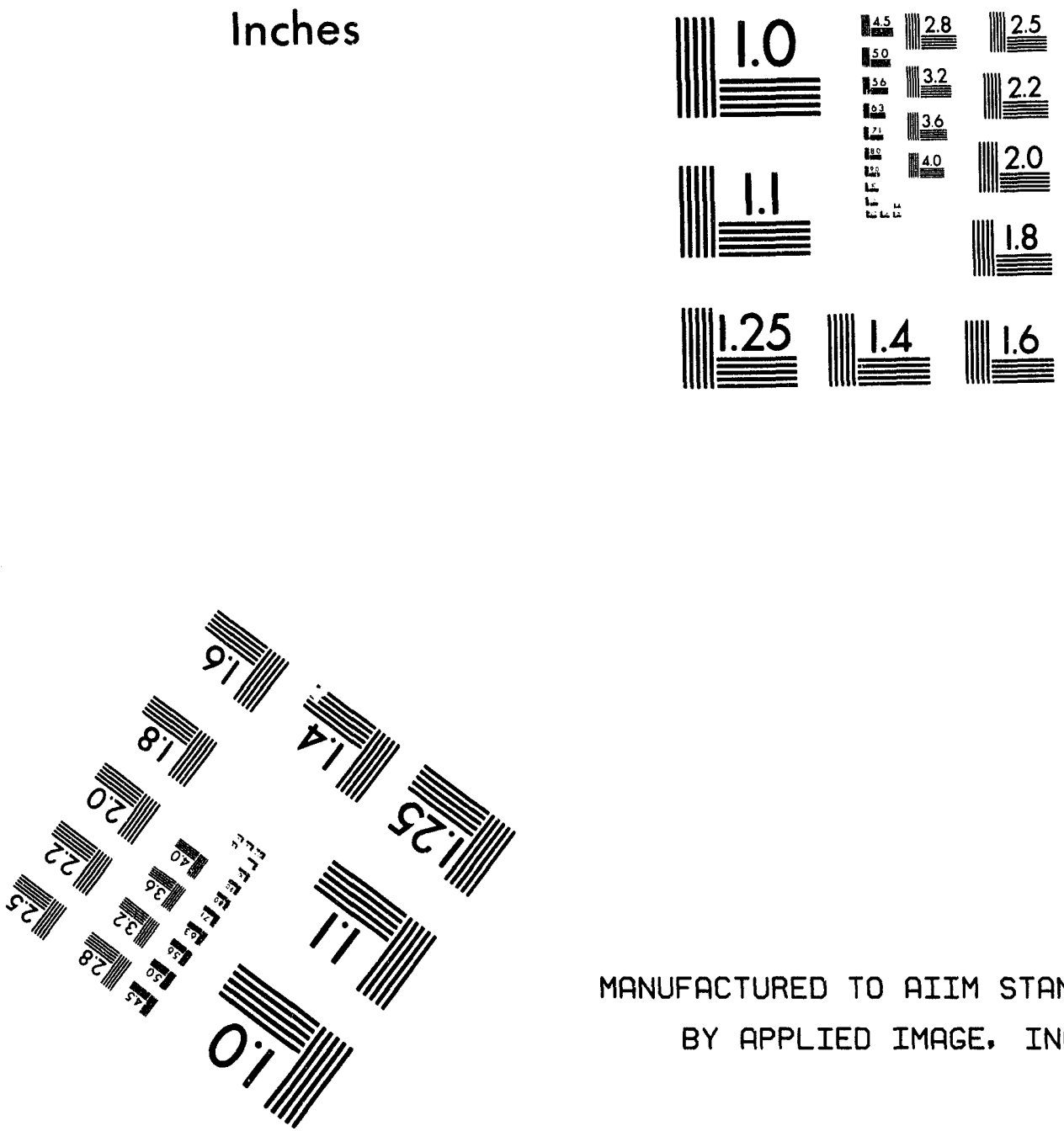

MANUFACTURED TO AIIM STANDARDS

BY APPLIED IMAGE, INC.

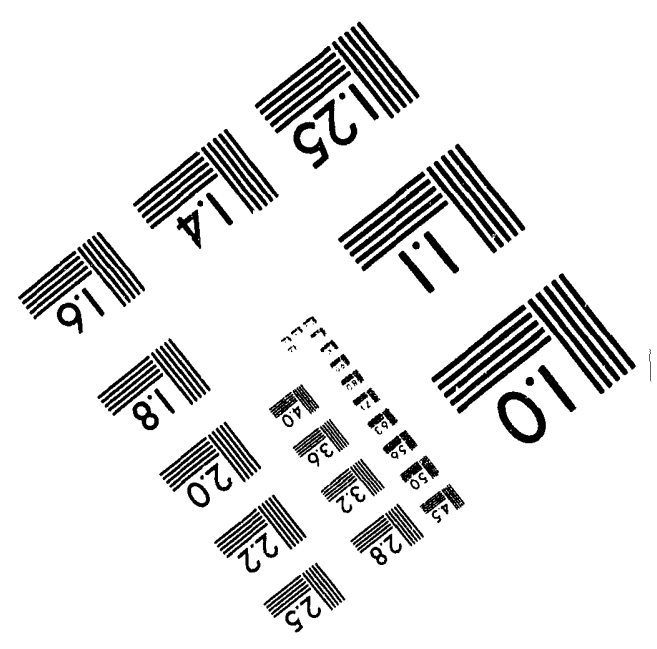



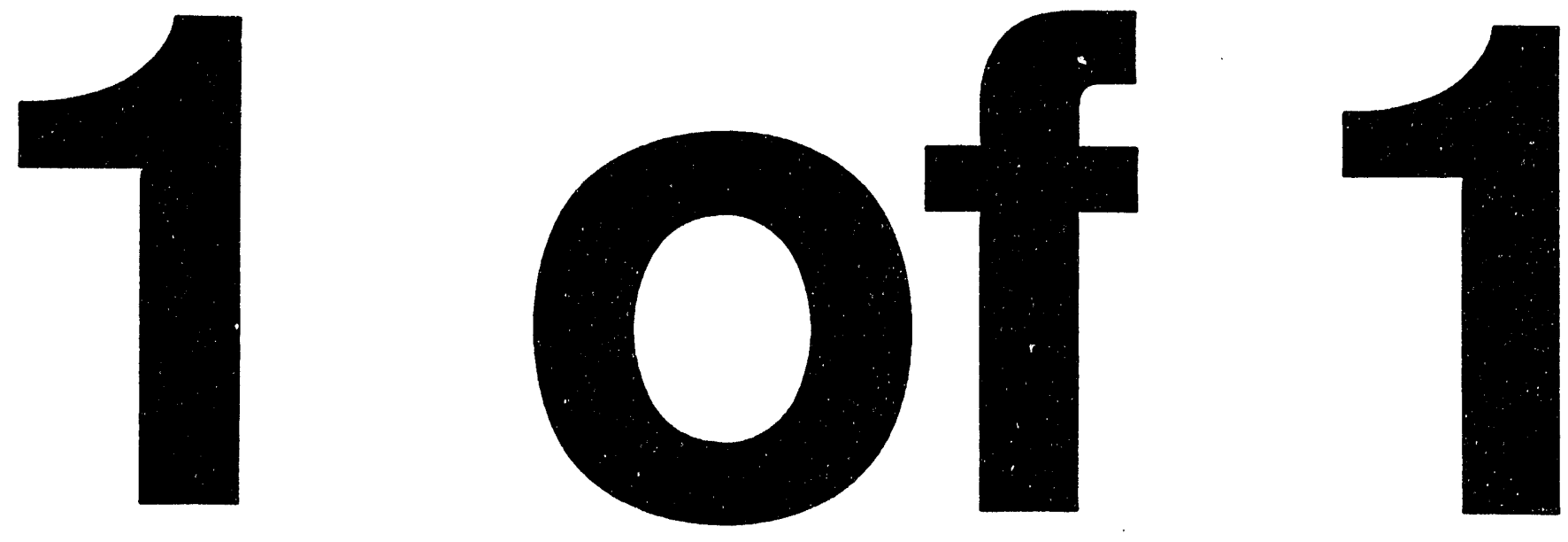
省1948SO

PPPL-3013

f UC-420,424
PREPARED FOR THE U.S. DEPARTMENT OF ENERGY, UNDER CONTRACT DE-AC02-76-CHO-3073

PPPL-3013

\section{DEUTERIUM-TRITIUM EXPERIMENTS}

ON THE TOKAMAK FUSION TEST REACTOR

BY

J. HOSEA, H. ADLER, P. ALLING, ET AL.

SEPTEMBER, 1994

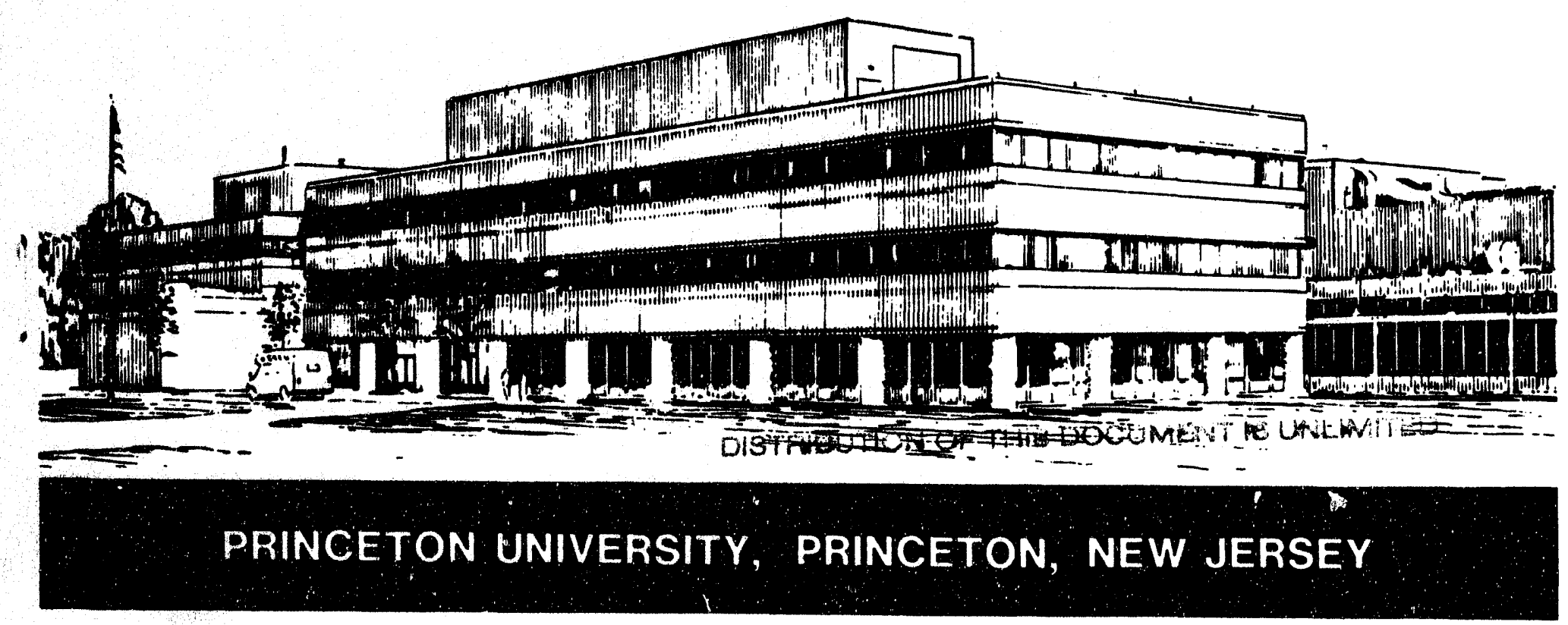




\title{
NOTICE
}

This report was prepared as an account of work sponsored by an agency of the United States Government. Neither the United States Government nor any agency thereof, nor any of their employees, makes any warranty, express or implied, or assumes any legal liability or responsibility for the accuracy, completeness, or usefulness of any information, apparatus, product, or process disclosed, or represents that its use would not infringe privately owned rights. Reference herein to any specific commercial produce, process, or service by trade name, trademark, manufacturer, or otherwise, does not necessarily constitute or imply its endorsement, recommendation, or favoring by the United States Government or any agency thereof. The views and opinions of authors expressed herein do not necessarily state or reflect those of the United States Government or any agency thereof.

\section{NOTICE}

This report has been reproduced from the best available copy. Available in paper copy and microfiche.

Number of pages in this report: 24

DOE and DOE contractors can obtain copies of this report from:

Office of Scientific and Technical Information

P.O. Box 62

Oak Ridge, TN 37831 ;

(615) $576-8401$.

This report is publicly available from the:

\author{
National Technical Information Service \\ Department of Commerce \\ 5285 Port Royal Road \\ Springfield, Virginia 22161 \\ (703) $487-4650$
}




\section{DEUTERIUM-TRITIUM EXPERIMENTS \\ ON THE TOKAMAK FUSION TEST REACTOR*}

J. Hosea, J, H. Adler, P. Alling, C. Ancher, H. Anderson, J.L. Anderson, a) J.W. Anderson, V. Arunasalam, G. Ascione, D. Ashcroft, C.W. Barnes, a) G. Barnes, S. Batha,b) M.G. Bell, R. Bell, M. Bitter, W. Blanchard, N.L. Bretz, C. Brunkhorst, R. Budny, T. Burgess, c) H. Bush,e) C.E. Bush,c) R. Camp, M. Caorlin, H. Carnevale, S. Cauffman, Z. Chang, f) C.Z. Cheng, J. Chrzanowski, J. Collins, G. Coward, M. Cropper, D.S. Darrow, R. Daugert, J. DeLooper, H. Duong, h) L. Dudek, R. Durst,f) P.C. Efthimion, D. Ernst, d) J. Faunce, R. Fisher, R.J. Fonck, f) E, Fredd, E. Fredrickson, N. Fromm, G.Y. Fu, H.P. Furth, V. Garzotto, C. Gentile, G. Gettelfinger, J. Gilbert, J. Gioia, T. Golian, N. Gorelenkov, i) B. Grek, L.R. Grisham, G. Hammeth, G.R. Hanson, c) R.J. Hawryluk, W. Heidbrink, j) H.W. Hermann, K.W. Hill, H. Hsuan, A. Janos, D.L. Jassby, F.C. Jobes,

D.W. Johnson, L.C. Johnson, J. Kamperschroer, J. Kesner, d) H. Kugel, S. Kwon, e) G.

Labik, N.T. Lam,f) P.H. LaMarche, E. Lawson, B. LeBlanc, M. Leonard, J. Levine, F.M. Levinton, b) D. Loesser, D. Long, M.J. Loughlin,k) J. Machuzak, d) D.K. Mansfield, M. Marchlik, e) E. S. Marmar, d) R. Marsala, A. Martin, G. Martin, V. Mastrocola, E. Mazzucato, R. Majeski, M. Mauel, ${ }^{1)}$ M.P. McCarthy, B. McCormack, D.C. McCune, K.M. McGuire, D.M. Meade, S.S. Medley, D.R. Mikkelsen, S.L. Milora, c) D. Mueller,

M. Murakami, c) J.A. Murphy, A. Nagy, G.A. Navratil, 1) R. Nazikian, R. Newman, T. Nishitani, m) M. Norris, T. O'Connor, M. Oldaker, J. Ongena, $\left.{ }^{n}\right)$ M. Osakabe, ${ }^{\prime}$ ) D.K. Owens, H. Park, W. Park, S.F. Paul, Yu.I. Pavlov,P) G. Pearson, F. Perkins,

E. Perry, R. Persing, M. Petrov, q) C.K. Phillips, S. Pitcher, r) S. Popovichev, P) R. Pysher, A.L. Qualls,c) S. Raftopoulos, R. Ramakrishnan, A. Ramsey, D.A. Rasmussen,c) M.H. Redi, G. Renda, G. Rewoldt, D. Roberts, f) J. Rogers, R. Rossmassler, A.L. Roquemore, E. Ruchov, j) S.A. Sabbagh, 1) M. Sasao, o) G. Schilling, J. Schivell, G.L. Schmidt, R. Scillia, S.D. Scott, T. Senko, R. Sissingh, C. Skinner, J. Snipes, d) P. Snook, J. Stencel,J . Stevens, T. Stevenson, B.C. Stratton, J.D. Strachan, W. Stodiek, E. Synakowski, W. Tang, G. Taylor, J. Terry, d) M.E. Thompson, J.R. Timberlake,

H.H. Towner, A. von Halle, C. Vannoy, R. Wester, R. Wieland, J.B. Wilgen, c)

M. Williams, J.R. Wilson, J. Winston, K. Wright, D. Wong, r) K.L. Wong, P. Woskov, d) G.A. Wurden, a) M. Yamada, A. Yeun, r) S. Yoshikawa, K.M. Young, M.C. Zarnstorff and S.J. Zweben

Princeton University Plasma Physics Laboratory P.O. Box 451

Princeton, NJ 08543

*Presented at the ANS Conference - Eleventh Topical Meeting on the Technology of Fusion Energy (New Orleans, June 19-23, 1994) 


\begin{abstract}
The deuterium-tritium (D-T) experimental program on the Tokamak Fusion Test Reactor (TFTR) is underway and routine tritium operations have been established. The technology upgrades made to the TFTR facility have been demonstrated to be sufficient for supporting both operations and maintenance for an extended D-T campaign. To date fusion power has been increased to $\sim 9 \mathrm{MW}$ and several physics results of importance to the D-T reactor regime have been obtained: electron temperature, ion temperature, and plasma stored energy all increase substantially in the D-T regime relative to the D-D regime at the same neutral beam power and comparable limiter conditioning; possible alpha electron heating is indicated and energy confinement improvement with average ion mass is observed; and alpha particle losses appear to be classical with no evidence of TAE mode activity up to the PFUS 6 MW level. Instability in the TAE mode frequency range has been observed at PFUS $>7 \mathrm{MW}$ and its effect on performance is under investigation. Preparations are underway to enhance the alpha particle density further by increasing fusion power and by extending the neutral beam pulse length to permit alpha particle effects of relevance to the ITER regime to be more fully explored.
\end{abstract}

\title{
I. INTRODUCTION
}

Routine tritium operations have been established on TFTR to support deuteriumtritium (D-T) experiments. A number of key systems needed for tritium operation have been added or modified for high auxiliary heating power, high radiation flux and/or tritium compatibility 1,2 and integrated into TFTR operations successfully. In particular, tritium delivery and exhaust systems have been added to the neutral beam injection systems to support combined high power tritium and deuterium injection ( $34 \mathrm{MW}$ thus far) required to achieve significant fusion power production. ${ }^{3}$ In addition, the conduct of operations discipline commensurate with the low hazard class III nuclear facility status of 
TFTR has been instituted to assure safe operational and maintenance activities, both for the high radiation levels associated with D-T plasmas and for handling tritium containing and tritium contaminated systems. ${ }^{4}$ These achievements have led to the first series of D-T experiments on a fusion facility encompassing the range of tritium concentrations (up to $\mathrm{D}: \mathrm{T} \sim 1: 1$ ) and core fusion power densities (up to $\sim 1.8 \mathrm{MW} / \mathrm{m}^{3}$ ) typical of those projected for the reactor/ITER 5 regime.

The first phase of D-T experiments on TFTR was directed toward establishing D-T operations with PFUS -5 MW to support a variety of physics studies of heating, confinement, and stability in the D-T regime including the effects of D-T isotope mixing and alpha particles. 6,7 The fusion power was increased up to a level of $6.2 \mathrm{MW}$ by increasing the tritium component of the neutral beam injection, resulting in a tritium to deuterium ratio in the plasma of $\mathrm{D}: \mathrm{T} \sim 1: 1$. With the high performance discharge reproducibility afforded by lithium pellet injection machine conditioning 8 and the ease of switching to the D-T regime from a comparison D-D regime (deuterium injection into a deuterium discharge at a comparable total beam power ), this level of fusion power proved to be sufficient to begin to discern important D-T effects. In particular, enhanced confinement with the addition of tritium is observed in both the supershot ${ }^{9}$ and limiter $\mathrm{H}$ mode ${ }^{10}$ regimes, possible alpha heating of electrons is suggested, ${ }^{11}$ toroidal Alfvén eigenmode (TAE) instability ${ }^{12}$ is not driven by the alpha particles at core fusion power densities up to $\sim 1.3 \mathrm{MW} / \mathrm{m}^{3}$, and direct tritium transport ${ }^{13}$ and recycling ${ }^{14}$ measurements reveal that tritium fueling from the limiter is small whereas deuterium fueling from the limiter is significant. This is consistent with a large fraction of the tritium being captured in the limiter through carbon codeposition trapping of gas during beam injection. 1,15

In the ongoing second phase of D-T experiments on TFTR, fusion power and alpha particle density are being maximized to support studies of even greater relevance to ITER and advanced tokamak regimes. Neutral beam supershot conditions are being optimized 
relative to discharge confinement and stability so as to permit a fusion power level of $\sim 10 \mathrm{MW}$ to be achieved. To date PFUS $\sim 9 \mathrm{MW}$ and a corresponding central fusion

power density of $\sim 1.8 \mathrm{MW} / \mathrm{m}^{3}$ have been obtained. At PFUS $>7 \mathrm{MW}$, a TAE-like mode is enhanced in keeping with theoretical projections for the TAE mode threshold. MHD instability is currently limiting the obtainable PFUS level and preparations are underway to increase the toroidal magnetic field from 5 Tesla to $\sim 6$ Tesla, thereby improving the MHD stability margin and permitting a further increase in the fusion power level.

In parallel with the D-T supershot optimization, ICRF heating of the core of large major radius D-T plasmas is being investigated for providing a basis for extrapolation to ITER. ICRF issues of interest include core heating in the supershot regime as a means of enhancing alpha particle density by increasing the alpha slowing down time, ${ }^{16}$ possibly assisting alpha excitation of TAE modes, serving as a method for alpha ash removal, and ultimately heating in the L-mode regime of possible relevance to ITER.

In the following section of this paper, key technology considerations for supporting routine tritium operations are presented briefly. Some of the more important physics results obtained to date are then presented and subsequently the goals of the continuing operations on TFTR and the operational scenarios planned to attain them are addressed.

\section{TECHNOLOGY CONSIDERATIONS FOR ROUTINE TRITIUM OPERATIONS IN TFTR}

A. Enhancements for Systems Reliability/Maintainability and Discharge Reproducibility

A number of technological enhancements have been made to the TFTR facility to permit tritium operations to be carried out successfully. ${ }^{1,2}$ Key considerations include tritium handling and accounting, operation at high auxiliary heating powers and high 
plasma stored energies, operation of diagnostics in a high neutron environment, and operation and maintenance of an activated machine and its attached systems.

Tritium handling and accounting required the commissioning of the tritium systems, ${ }^{17}$ their integration with the torus and neutral beam gas injection and vacuum exhaust systems, ${ }^{18}$ and verification of the tritium monitoring instrumentation. ${ }^{3}$ The introduction of tritium for the experiments has been supported via these processes with an on-site tritium shipment of $\sim 25 \mathrm{kCi}$ each two operating weeks being balanced by a similar curie amount of tritiated water being shipped off-site during the same period. A substantial effort has been directed toward bringing the many vital systems of this ritium handling network to the level of reliability required for routine tritium operations and for minimizing maintenance requirements. The accounting verification has been important to assure that the site technical safety requirements of site and location inventories of $50 \mathrm{kCi}$ and $25 \mathrm{kCi}$, respectively, are not exceeded for all tritium transfer operations.

Operation at high auxiliary heating powers and high plasma stored energies in TFTR and the desire to do so under reproducible plasma conditions has resulted in considerable emphasis being placed on the power handling capability of the internal vessel hardware, especially the bumper limiter, and on limiter conditioning techniques. The bumper limiter is located on the inner radius side of the torus and a final upgrade to this limiter consisting of placing tapered graphite and carbon-carbon composite rows at its top and bottom respectively was made prior to beginning D-T operations. ${ }^{19}$ This upgrade has proven successful in reducing carbon blooms under normal supershot plasma conditions with up to $34 \mathrm{MW}$ of applied auxiliary heating power. The improved limiter configuration combined with lithium pellet injection both prior to and after the neutral beam injection pulse has resulted in reproducible high performance supershot operation on TFTR and the ability to carry out meaningful comparisons between high performance D-T and D-D supershots. 6,7 
The high neutron fluxes (up to $3.2 \times 10^{18} \mathrm{n} / \mathrm{sec}$ at present) and the substantial machine activation $\left(\sim 50 \mathrm{mrem} / \mathrm{hr}\right.$ at the vessel at present $\left.{ }^{20}\right)$ which accompany the high performance D-T operation have necessitated system enhancements as well. In particular, neutron and radiation shielding upgrades for neutron/gamma sensitive diagnostics such as spectrometers and lost $\alpha$ scintillation detectors have proven to be adequate to keep these diagnostics functioning to date. Also, the maintenance of diagnostics and machine systems has been facilitated with suitable modifications. For example, the lithium pellet injector, which is located near the TFTR torus, has been retrofitted with a pump-purge vacuum arrangement to permit rapid changeout of the pellet magazine in the tritium contaminated system. Also, the coolant in the toroidal field coil system has been changed to Fluorinert ${ }^{\mathrm{TM}}$ to obviate the need to make time consuming repairs to leaks in a high radiation environment. ${ }^{21}$

\section{B. Tritium Neutral Beam Injection}

The centerpiece of tritium operations on TFTR is the neutral beam injection system. This system is comprised of four beam lines with the configuration shown in Fig. 1, each having three beam sources. Each source can be individually selected to operate with deuterium or tritium for any given plasma discharge affording considerable flexibility in choosing co-counter beam gas compositions. The beam line cryopanels serve to pump both deuterium and tritium for subsequent regeneration to the tritium processing system, which converts these gases to water for shipping off site.

The amount of tritium required to support the beam source operation and the ion beam neutralization is $\sim 200 \mathrm{Ci}$ for a $1 \mathrm{sec}, 3 \mathrm{MW}$ beam source pulse. Of this amount of tritium, $\sim 3.5 \%$ is introduced into the torus in the energetic neutral beam and the remainder is captured on the beamline cryopanels. In order to limit the tritium inventory required to 
sustain tritium beam operation, the technique of conditioning the beam source in deuterium between plasma shots and then switching to tritium just for the plasma shot has been developed successfully. ${ }^{22}$ The ion sources are conditioned by pulsing every 2.5 minutes into either the beamline calorimeters at full pulse length during daily start up or the torus protective plates at $50 \mathrm{msec}$ pulse length once beam injection operations have begun. This sequence is illustrated in Fig. 2. The key to its success is the ability to quickly reset the ion source and beam line operating parameters with a programmable logic controller (PLC) to select the source perveance and ion dump magnetic field to match the working gas. Beam spectroscopy indicates that the ion source isotope exchange is $-98 \%$ complete for tritium injection and is $>99.5 \%$ complete for deuterium injection.

\section{EXPERIMENTAL RESULTS}

The sustained tritium operations afforded by the TFTR facility has led to a series of important results pertaining to fusion power production, heating and confinement, stability, and transport and recycling.

\section{A. Fusion Power}

The first series of high power deuterium-tritium (D-T) beam injection discharges on TFTR were conducted at a plasma current (IP) of 2.0 MA, a toroidal magnetic field (BT) of $5.0 \mathrm{~T}$, a major radius (R) of $2.52 \mathrm{~m}$, a minor radius (a) of $0.87 \mathrm{~m}$, and a maximum neutral beam power of $30 \mathrm{MW}$. The fusion power production was pushed to above $6 \mathrm{MW} .6,7$ Collimated vertical cord measurements of neutrons (10 NE 451 and $10 \mathrm{ZnS}$ scintillators, $5 \mathrm{He}-4$ proportional counters located below the torus in the basement) show clearly that the neutron flux peaked strongly on axis as expected. The $14 \mathrm{MeV}$ neutron production at the peak fusion power was $2.2 \times 10^{18} \mathrm{n} / \mathrm{sec}^{6}$ The fusion power density on axis was $\sim 1.3 \mathrm{MW} / \mathrm{m}^{3}$, comparable to that projected for ITER, 5 and the alpha particle 
heating power, central density, and central/average $\beta_{\alpha}$ were $0.86 \mathrm{MW}, 1.3 \times 10^{17} \mathrm{~m}^{-3}$ $\left[\mathrm{n}_{\alpha}(0) / \mathrm{n}_{\mathrm{e}}(0) \sim 0.17 \%\right]$ and $2.2 \times 10^{-3 / 3.0} \times 10^{-4}$, respectively, as detailed in Refs. 6 and 7 .

In the current series of high power D-T injection discharges, the plasma current and maximum neutral beam power have been increased to $-2.5 \mathrm{MA}$ and $33.7 \mathrm{MW}$, respectively, with $R$ and a maintained at $2.52 \mathrm{~m}$ and $0.87 \mathrm{~m}$, respectively. In addition, lithium pellet injection conditioning has been added to the D-T plasma. Under these conditions, fusion power has been pushed to $\sim 9 \mathrm{MW}$ as shown in Fig. 3, at which time the discharge terminated in a major disruption. The $14 \mathrm{MeV}$ neutron production at the peak fusion power was $3.2 \times 10^{18} \mathrm{n} / \mathrm{sec}$, and the fusion power density on axis increased to $\sim 1.8 \mathrm{MW} / \mathrm{m}^{3}$.

\section{B. Heating and Confinement}

The initial heating and confinement data for the D-T regime are presented in Ref. 6 where it is revealed that significant electron and ion heating occur in D-T relative to the comparable D-D case $\left[\mathrm{T}_{\mathrm{e}}(0): 9.5 \rightarrow 10.3 \mathrm{keV}\right.$ and $\mathrm{T}_{\mathrm{i}}(0): 30 \rightarrow 37 \mathrm{keV}$ for $\mathrm{n}_{\mathrm{e}}(0) \sim 7.6 \times$ $10^{19} \mathrm{~m}^{-3}$ at $3.4 \mathrm{sec}$ in the discharge], resulting in an equally significant increase in stored energy ( $\mathrm{W}_{\text {tot: }} 4.2 \rightarrow 4.9 \mathrm{MJ}$ ). Commensurate with these increases, the energy confinement time increased from $150 \mathrm{msec}$ to $180 \mathrm{msec}$. The corresponding results for the cases shown in Fig. 3 reveal further enhancement in these parameters, as indicated by an observed increase in confinement time to $\sim 240 \mathrm{msec}$ for the PFUS $\sim 9 \mathrm{MW}$ case. Correspondingly, $\mathrm{T}_{\mathrm{e}}(0), \mathrm{T}_{\mathrm{i}}(0), \mathrm{W}_{\text {tot }}$ and $\mathrm{n}_{\mathrm{e}}(0)$ increased to $\sim 11.5 \mathrm{keV}, \sim 40 \mathrm{keV}, \sim 6.5 \mathrm{MJ}$, and $8.5 \times 10^{19} \mathrm{~m}^{-3}$, respectively. The triple product $n_{i}(0) \tau^{*}{ }^{*} T_{i}(0)$ increased to $\sim 5.2 \times$ $10^{20} \mathrm{~m}^{-3} \bullet \mathrm{sec} \bullet \mathrm{keV}$ up from $4.4 \times 10^{20} \mathrm{~m}^{3} \bullet \mathrm{sec} \bullet \mathrm{keV}$ in the best TFTR deuterium case where $\tau_{\mathrm{E}^{*}}=\mathrm{W}_{\text {tot }} / \mathrm{PNB}^{2}{ }^{2}$

Differences in electron and ion heating, as well as for the energy confinement time, are predicted between the D-D and D-T regimes due to such effects as an increase in beam 
thermalization time for the tritium beams, broader deposition profile for the tritium beams, the energy stored in the energetic alpha population, and additional heating of the electrons by the alpha particles. ${ }^{11}$ Additional differences can also occur if the ion isotopic mix change between the D-D and D-T regimes affects the energy confinement of either ions or electrons or both.

The TRANSP interpretive code, ${ }^{11}$ applied as discussed in Ref. 6, is used to produce the comparisons in Fig. 4 between the $T_{e}$ data for the D-D and D-T (PFUS $~ 6.2 \mathrm{MW}$ case of Refs. 6 and 7) regimes and the code predictions using the thermal electron diffusivity for the D-D case, with and without alpha heating. Alpha heating is consistent with part of the increase in electron temperature and an isotopic dependence of the thermal electron diffusivity is indicated as well. Similarly, the increase in ion temperature points to an isotopic dependence of the thermal ion diffusivity. The global energy confinement time is found to increase with average hydrogenic ion mass (Fig. 5) as the fraction of tritium beam injection is increased.

This isotopic dependence of energy confinement time has been found recently to apply as well to the limiter H-mode D-T regime. In particular, the enhancement factor for energy confinement time over the ITER-89P value 23 has been observed to increase from $\sim 3$ to $\sim 4$ from the D-D to the D-T regime $\left(I_{p}=1.2 \mathrm{MA}\right.$ PFus $=3-4 \mathrm{MW}, \mathrm{PNBI}_{\mathrm{N}}=23 \mathrm{MW}$, after current ramp down). This result is of particular relevance for projecting to ITER confinement in the H-mode and is consistent with the isotope effects observed in other enhanced-confinement $\mathrm{H}$-mode studies performed in hydrogen and deuterium. 24

ICRF heating studies for the D-T supershot regime are being pursued as well. Helium-3 minority/tritium secord harmonic heating has been used successfully with PICRF $\approx 5.5 \mathrm{MW}$ added to $\mathrm{PNB} \approx 23 \mathrm{MW}$ to enhance $\mathrm{T}_{\mathrm{i}}(0)$ and $\mathrm{T}_{\mathrm{e}}(0)$ from $27 \rightarrow 33$ $\mathrm{keV}$ and $8 \rightarrow 11 \mathrm{keV}$, respectively, while neutron emission increased by $\sim 10 \% .25$ 
Experiments have been conducted using modulated RF power to evaluate the wave damping characteristics and their projections to ITER parameters. Preliminary analysis indicates that the tritium second harmonic damping agrees with theoretical modelling while off-axis deuterium fundamental damping is much smaller than predicted. Direct electron heating is also being pursued via fast wave mode conversion into a localized slow wave in the two-ion plasma regime. ${ }^{26}$ Initial results are quite promising with only $\sim 3 \mathrm{MW}$ of ICRF power required to increase $T_{e}$ from $-3 \rightarrow \sim 6 \mathrm{keV}$ in a $\mathrm{He}^{3}: \mathrm{He}^{4}: \mathrm{D}$ plasma $\left[\mathrm{n}_{\mathrm{i}} / \mathrm{n}_{\mathrm{e}}\right.$ $-0.17: 0.14: 0.29$ with $\left.n_{e}(0) \approx 4 \times 10^{19} \mathrm{~m}^{-3}\right]^{27}$

\section{Stability}

The MHD activity observed for the D-T regime in the first series of experiments 6.7 was rather benign with the noticeable absence of a major $\beta$ collapse in the core, such as was observed for the two tritium beam source plasma discharges produced on the Joint European Torus (JET) in 1991.28 However, a growing coherent $\mathrm{m} / \mathrm{n}=4 / 3$ mode did accompany the fusion power rollover observed for the highest neutral beam injection power of $6.2 \mathrm{MW}$. A similar rollover in neutron emission accompanied by MHD activity has been noted for D-D plasmas. Studies of the correlation of MHD modes to $\tau E$ in the DD case ${ }^{29}$ indicate that a decrease in stored energy of $\sim 10 \%$ could have been caused by the $\mathrm{m} / \mathrm{n}=4 / 3$ activity. Since PFUS $\propto \mathrm{W}_{\text {tot }^{2}}$ in the highest performance supershots, ${ }^{30}$ the decrease in fusion power of $\sim 30 \%$ over the pulse could be due largely to the effects of this instability combined with temporary reductions in the applied neutral beam power. ${ }^{7}$ As discussed later, limiter recycling fueling could contribute to this decease as well, especially through increased hydrogen influx from the plasma edge.

With the increase in performance to the conditions of Fig. 3, the first important result that is evident is that the rollover for the PFUS $-6.4 \mathrm{MW}$ case has been greatly reduced with the increase in IP to $2.47 \mathrm{MA}$ from $2 \mathrm{MA}$ and with the application of lithium pellet 
conditioning with one pellet preceding and another following the neutral beam injection period. These changes resulted in the elimination of the $m / n=4 / 3$ MHD mode activity. With the further increase in neutral beam power to $33.5 \mathrm{MW}$, the PFUS increased to $\sim 7.5 \mathrm{MW}$ but the rollover accompanied by $\mathrm{m} / \mathrm{n}=5 / 4 \mathrm{MHD}$ mode activity returned (Fig. 3). Upon increasing the lithium pellets from two to three (two before the neutral beam injection period), a $\beta$ collapse was apparent on shot \#76773. Subsequently, following D-D conditioning discharges the three lithium pellet case of shot \#76778 (Fig. 3) was obtained. MHD mode activity was absent for this case until just prior to the high $\beta_{\mathrm{N}}$ disruption being encountered at $3.94 \mathrm{sec}$. The stored energy in the plasma at the time of the disruption was $6.5 \mathrm{MJ}$ with $\left[\beta_{\mathrm{N}} \equiv \beta_{\mathrm{T}}(\%) \bullet \mathrm{a}(\mathrm{m}) \bullet \mathrm{BT}(\mathrm{T}) / \mathrm{I}_{\mathrm{p}}(\mathrm{MA}) \approx 1.8\right]$ which is higher than the 5.7 MJ value supported under the best conditions obtained to date in the D-D regime. $^{2}$

In the first series of D-T experiments, the fusion power density on axis reached $\sim 1.3 \mathrm{MW} / \mathrm{m}^{3}$, and at that level the alpha particle $\beta$ was predicted to have approached that required to produce the alpha driven toroidal Alfven eigenmode (TAE) ${ }^{31}$ as indicated in Fig. 6. Up to the PFUS 6.2 MW level, there was no indication that mode activity in the TAE mode frequency range was enhanced by the presence of alphas produced in the D-T supershot plasma, even following the termination of beam heating where the conditions should be more conducive to alpha driven TAE modes. ${ }^{7}$ However, the conditions obtained for $6.2 \mathrm{MW}$ of fusion power (Fig. 6) suggested that TAE mode activity and its effects might be observed if the fusion power is increased further.

Prior to increasing fusion power levels, TAE mode activity in the D-T regime was investigated in the presence of ICRF heating. In particular, the power threshold for ICRF excitation of TAE modes ${ }^{32}$ has been observed to decrease in the transition from the D-D regime to the D-T regime. Figure 7 shows that in the D-T plasma, TAE modes were driven into saturation at $P R F=5.2 \mathrm{MW}$, the power threshold in D-D. The TAE mode 
continued to be driven in the D-T case at PRF $=4 \mathrm{MW}$ for which there was no sign of TAE activity in the D-D case. This preliminary result suggests that alpha particles may have assisted the energetic ICRF driven hydrogen ions in driving TAE modes. However, a definitive conclusion must await further analysis of the isotopic mixing effect on the ICRF driven energetic ion tail distribution and on TAE mode damping.

Upon increasing the fusion power further (Fig. 3), the TAE-like mode was enhanced as shown on a magnetic probe signal 33 in Fig. 8. For PFUS $=7.5 \mathrm{MW}$, the alpha particle density and central/average $\beta_{\alpha}$ are calculated to have been $1.9 \times 10^{17} \mathrm{~m}^{-3}\left[\mathrm{n}_{\alpha}(0) / \mathrm{n}_{\mathrm{e}}(0) \sim\right.$ 0.26 ] and $2.6 \times 10^{-3} / 3.2 \times 10^{-4}$, respectively. The threshold of this mode enhancement is consistent with that predicted for alpha particle excitation (Fig. 6). Studies to determine if this mode in turn affects the alpha particle transport properties are on-going.

\section{Particle Recycling and Transport}

Pure tritium beam injection resulted in a significant neutron production, reaching 65\% of the maximum D-T neutron emission observed for near equal injected powers for deuterium and tritium. ${ }^{7}$ This result indicates that a large concentration of deuterium $(\sim 40 \%)$ was maintained by limiter recycling fueling of deuterium and subsequent transport to the plasma core. The first measurements of tritium, deuterium, and hydrogen recycling in combination have been made on TFTR by resolving spectroscopic Balmer-alpha line emission $\left(T_{\alpha}, D_{\alpha}, H_{\alpha}\right){ }^{14}$ These measurements show that deuterium recycling is dominant for all of the D-T cases studied. Following an extensive campaign of D-T operation, a maximum value of $\mathrm{T}_{\alpha} /\left(\mathrm{H}_{\alpha}+\mathrm{D}_{\alpha}+\mathrm{T}_{\alpha}\right)$ of only $\sim 7 \%$ was observed. The data support the recycling model developed previously on TFTR ${ }^{34}$ where a rapid dilution of surface gas occurs over a short period of $\sim 10$ discharges and is followed by a much slower diffusion of the bulk limiter gas to the limiter surface. Thus, a complex process dependent on the recycling properties of a succession of discharges, the transport 
parameters of the various ion species, and the direct neutral beam deposition profiles determines the relative ion species concentrations in the D-T regime. This process of potential tritium dilution and density profile broadening could contribute to the roll off of fusion power which remains at reduced levels of MHD activity (PFUS 6.4 MW case of Fig. 3).

Transport of tritium to the core of a deuterium beam driven supershot plasma has been readily observed by monitoring the $14 \mathrm{MeV}$ neutron emission profile resulting from a short puff of tritium gas at the edge of the plasma. ${ }^{13}$ These measurements show that the particle diffusivity $D \approx 1 \mathrm{~m}^{2} / \mathrm{sec} @ \mathrm{r} / \mathrm{a} \sim 0.5$ is comparable to the thermal diffusivity across the profile and that there is an inward pinch of $\mathrm{V} \leq 1 \mathrm{~m} / \mathrm{sec} @ \mathrm{r} / \mathrm{a} \sim 0.5$. These values are comparable to those obtained earlier from He puff experiments ${ }^{35}$ except that preliminary analysis suggests that the central diffusivity is somewhat higher for the tritium case resulting in a flatter central tritium density profile.

Transport of energetic alpha particles from the core of the plasma and their subsequent loss from the plasma are topics of considerable importance for the D-T reactor regime. Measurements of fusion alpha particles escaping from the plasma with a scintillation detector ${ }^{36}$ (located near the vacuum vessel wall $90^{\circ}$ below the midplane in the ion-gradient magnetic field drift direction) revealed that in the experiments for PFUS up to 6.2 MW the alpha loss rate to the detector is proportional to the neutron (alpha production) rate. ${ }^{7}$ This result supports the conclusion that alpha driven instabilities (e.g. TAE modes) are not causing a substantial global loss of alpha particles up to central fusion power densities of $\sim 1.3 \mathrm{MW} / \mathrm{m}^{3}$. However, further study is required to determine if the enhanced TAE-like mode activity observed at higher fusion powers affects alpha particle confinement and if localized surface deposition of alpha particles due to core instabilities are important. 
In an attempt to assess the possible influence of ICRF heating on alpha trans port and ultimately ash removal, modulated ICRF power is being applied to the D-T supershot regime. 37 In Fig. 9, the alpha loss to the $90^{\circ}$ scintillation detector is shown to have a sizable modulation correlated with that imposed on the RF power. The pitch angle and gyroradius of the modulated detector signal correspond to those of energetic alpha particles and lead to the conclusion that the ICRF power heats barely passing alpha particles at their second harmonic layer and moves them into the first orbit loss cone.

\section{CONTINUING D-T OPERATIONS ON TFTR AND CONCLUSIONS}

The on-going D-T operations on TFTR are directed toward attaining $\sim 10 \mathrm{MW}$ of fusion power and enhancing the alpha particle density to support physics studies of relevance to the reactor/ITER regime. In addition to enhancing the fusion power with increased neutral beam injection power accompanied with optimization of lithium pellet injection discharge conditioning, 8 preparations are nearing completion to support an increase in the toroidal magnetic field BT to $\sim 6$ Tesla $(R=2.48 \mathrm{~m})$. The peak $D-D$ neutron rate is observed to follow an $\mathrm{I}^{4} \mathrm{TF}$ dependence up to $72 \mathrm{kA}(\mathrm{BT} \approx 5 \mathrm{~T}$ for $\mathrm{R}=2.52$ $\mathrm{m})$ as shown in Fig. 10. If this dependence can be maintained, the increase in magnetic field to 6 Tesla should provide a factor of $\sim 1.7$ increase in the neutron rate and hence the fusion power.

At the 6 to $10 \mathrm{MW}$ level of fusion power, the projected TFTR alpha particle parameters are $n_{\alpha}(0) / n_{e}(0) \sim 0.17-0.4 \%, R \Delta \beta_{\alpha} \sim 0.03-0.04$, and $V_{\alpha} / V_{\text {Alfven }} \sim 1.5-2.0$. From the point of view of alpha physics issues, these parameters are close (factors of $\sim 2$ to 3) to those projected for ITER, 5 and thus the TFTR alpha physics results are of direct relevance to ITER. Additional alpha core density for large major radius plasmas will be provided by increasing the alpha slowing down time with ICRF core electron heating 16 to further accentuate potential alpha particle loss at the outer vessel midplane and its possible 
enhancement by instabilities such as the TAE mode. Finally, longer pulse tritium beam operation is being explored to further increase the alpha population. Optimization of alpha particle buildup will require that the rollover observed at higher fusion powers be minimized. This optimization in the D-T regime over a few seconds is a necessary first step to maintaining high performance D-T reacting plasmas for much longer periods of time in advanced reactor concepts.

The D-T physics results obtained to date on TFTR have begun to provide a basis for extrapolation to D-T plasmas on ITER. It is clear that MHD stability remains an overriding concern in obtaining optimized reactor performance. Ar increase in the toroidal field to $\sim 6$ Tesla should permit stable operation to fusion powers $\sim 10 \mathrm{MW}$ and techniques to avoid disruptions and $\beta$ collapses continue to be explored to maximize alpha density buildup. Such conditions on TFTR are well suited for the task of establishing the alpha particle physics basis for directly supporting the ITER design.

\section{ACKNOWLEDGMENTS}

Preparations for and performing of the deuterium-tritium experiments have entailed a tremendous effort by the technical, engineering, and research staff of the Princeton Plasma Physics Laboratory and by participants from national and international laboratories, universities, and industry. Their effort and support are gratefully acknowledged.

Work supported by U.S. Department of Energy Contract No. DE-AC02-76-CHO3073. 

a) Los Alamos National Laboratory, Los Alamos, New Mexico.
b) Fusion Physics and Technology, Torrance, California
c) Oak Ridge National Laboratory, Oak Ridge, Tennessee.
d) Massachusetts Institute of Technology, Cambridge, Massachusetts.
e) EBASCO.
f) University of Wisconsin, Madison, Wisconsin
g) University of California, Los Angeles, California
h) General Atomics, San Diego, California.
i) TRINIII, Moscow, Russia.
j) University of California, Irvine, California.
k) JET Joint Undertaking, Abingdon, England
l) Columbia University, New York, New York.
m) JAERI Naka Fusion Research Establishment, Naka, Japan.
n Ecole Royale Militaire, Brussels, Belgium.
o) National Institute of Fusion Studies, Nagoya, Japan.
p) RRC Kurchatov Institute, Moscow, Russia.
q) Ioffe Physical-Technical Institute, Russia.
r) Canadian Fusion Fuels Technology Project, Toronto, Canada.

\section{REFERENCES}

1 R.J. Hawryluk, D. Mueller, J. Hosea, et al., Fusion Technology, 21 (1992) 1324.

2 R.J. Hawryluk, H. Adler, P. Alling, et al., Physics of Plasmas 1 (1994) 1560.

3 P. LaMarche, J.L. Anderson, et al., "Tritium Processing and Management During D-T Experiments on TFTR", this conference, Tuesday AM, June 21.

4 M. Leonard et al., Proceedings of the 15th IEEE/NPSS Symposium on Fusion Engineering 1993 (IEEE Pub. 93CH3348-0, 1994) Vol. 2, p. 1016.

5 D.E. Post, Plasma Physics and Controlled Nuclear Fusion Research 1990) (IAEA, Vienna, 1991) Vol. 3, p. 239.

6 R.J. Hawryluk, H. Adler, P. Alling, et al., Phys. Rev. Lett. 72 (1994) 3530.

7 J.D. Strachan, H. Adler, P. Alling, et al., Phys. Rev. Lett. 72 (1994) 3526.

8 J. Terry, E. Marmar, R. Howell, et al., Plasma Physics and Controlled Nuclear Fusion Research, 1990 (IAEA, Vienna, 1991) Vol. p. 393; D. Jassby, D. Mansfield, M. Bell, et al., "High-performance Supershots in TFTR with Lithium Pellet Injection," submitted to Nuclear Fusion.

9 J. Strachan et al., Phys. Rev. Lett. 58 (1987) 1004.

10 C. Bush et al., Plasma Physics and Controlled Nuclear Fusion Research, 1990 (IAEA, Vienna, 1991), Vol. 1, p. 309.

11 R. Budny et al., Nuclear Fusion 32 (1992) 32.

12 K.L. Wong et al., Phys. Rev. Lett. 66 (1991) 1874.

13 P. Efthimion et al., "Tritium Transport, Recycling, and Gas Fueling Experiments on TFTR," to be published.

14 C. Skinner et al., "First Measurements of Tritium Recycling in TFTR," Princeton Plasma Physics Report PPPL-2993 (1994), submitted to Nuclear Fusion. 
15 H. Dylla and K. Wilson, "Tritium Retention in TFTR," Princeton Plasma Physics Laboratory Report PPPL-2523 (1988) and Sandia National Laboratory Report SAND88.8212 (1988); M. Ulrickson et al., J. Vac. Sci. Technol. A6 (1988) 2001.

16 G. Taylor et al., Plasma Phys. Control. Fusion 36 (1994) 523.

17 J.L. Anderson et al., Proceedings of the 15th IEEE/NPSS Symposium of Fusion Engineering 1993 (IEEE Pub. 93CH3348-0, 1994) Vol. 1, p. 208.

18 E. Perry and L. Dudek, ibid., Vol. 2, p. 818

19 M. McSmith, G.Loesser, and D.K. Owens, "Modification and Final Alignment of the TFTR Bumper Limiter," this conference, Wednesday AM, June 22.

20 H. Kugel et al., "Measurements of D-T Radiation Shielding Efficiency," to be presented at the 3rd Int. Symposium on Fusion Nuclear Technology (Los Angeles, June 27-July 1, 1994).

21 G. Walton et al., Proceedings of the 15th IEEE/NPSS Symposium of Fusion Engineering 1593 (IEEE Pub. 93CH3348-0, 1994) Vol. I, p. 325; G. Barnes et al., ibid, Vol. 1, p. 329.

22 TFTR D-T Plan Document OPR-R-12.

23 P. Yushmanov et al., Nuclear Fusion 30 (1990) 1989.

24 M. Bessenrodt-Weberpals et al., Nuclear Fusion 33 (1993) 1205.

25 G. Taylor et al., "ICRF Heating of Deuterium-Tritium Plasma in TFTR," to be published.

26 R. Majeski et al., Radio Frequency Power in Plasmas, 1993 (AIP Conference Proceedings 289, 1994) p. 401.

27 R, Majeski et al., "Mode Conversion Studies in TFTR," to be published.

28 The JET Team, Nuclear Fusion 32 (1992) 187.

29 Z. Chang et al., "Transport Effects of Low (m, n) MHD Modes on TFTR Supershots," Princeton Plasma Physics Laboratory Report PPPL-2941 (1993), submitted to Nuclear Fusion.

30 D. Jassby et al., Physics of Fluids B 3(1991) 2308.

31 C. Cheng et al., Plasma Phys. and Contr. Nucl. Fus. Res. 1992 (IAEA, Vienna, 1993) Vol. II, p. 51.

32 J.R. Wilson et al., Plasma Phys. and Contr. Nucl. Fus. Res. 1992 (IAEA, Vienna, 1993) Vol. I, p. 661.

33 E. Fredrickson et al., Rev. Sci. Instrum 59 (1988) 1797.

34 P. LaMarche et al., J. Vac Sci. Technol. 1, A4 (1986) 1198.

35 E. Synakowski et al., Phys. Fluids B 5 (1993) 2215.

36 S. Zweben et al., to be published in Phys. Fluids B.

37 D. Darrow et al., to be published. 


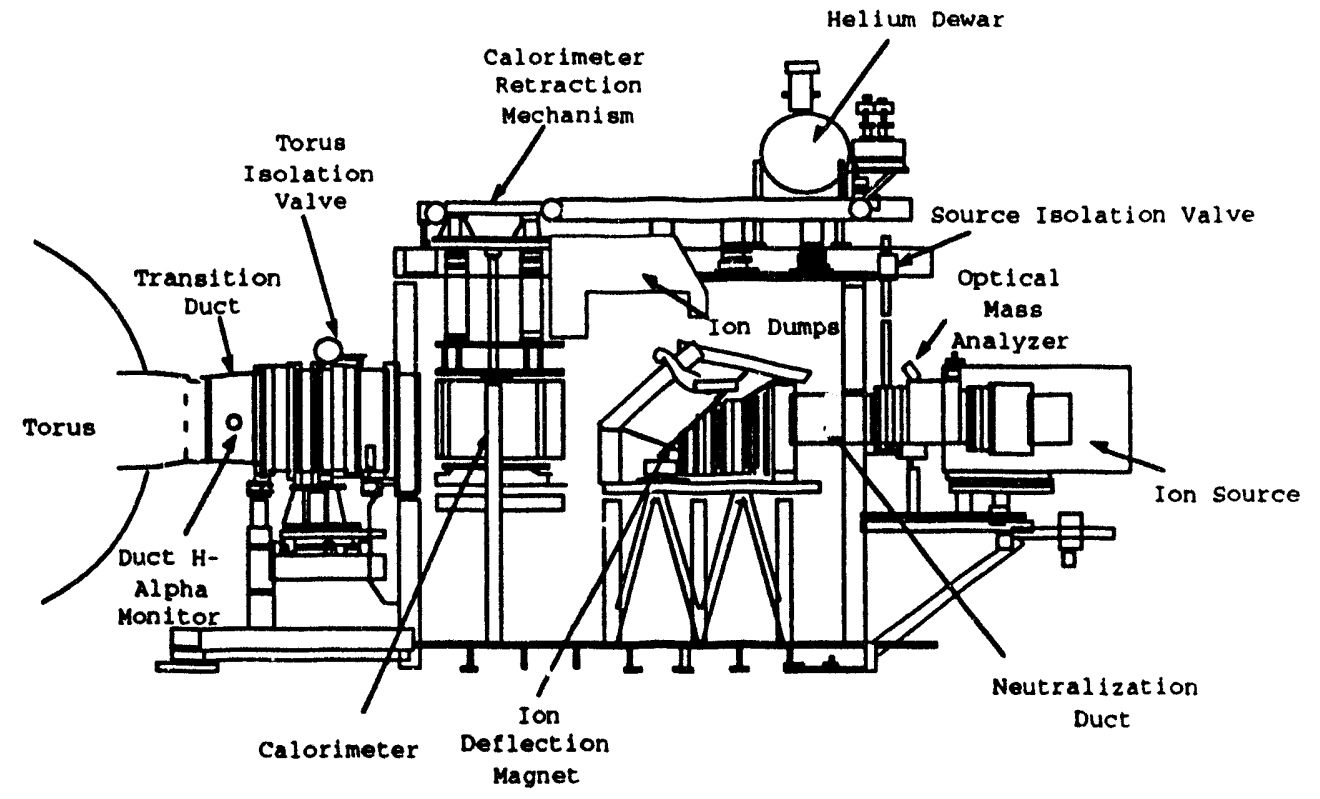

Fig. 1 The TFTR beamline configuration.

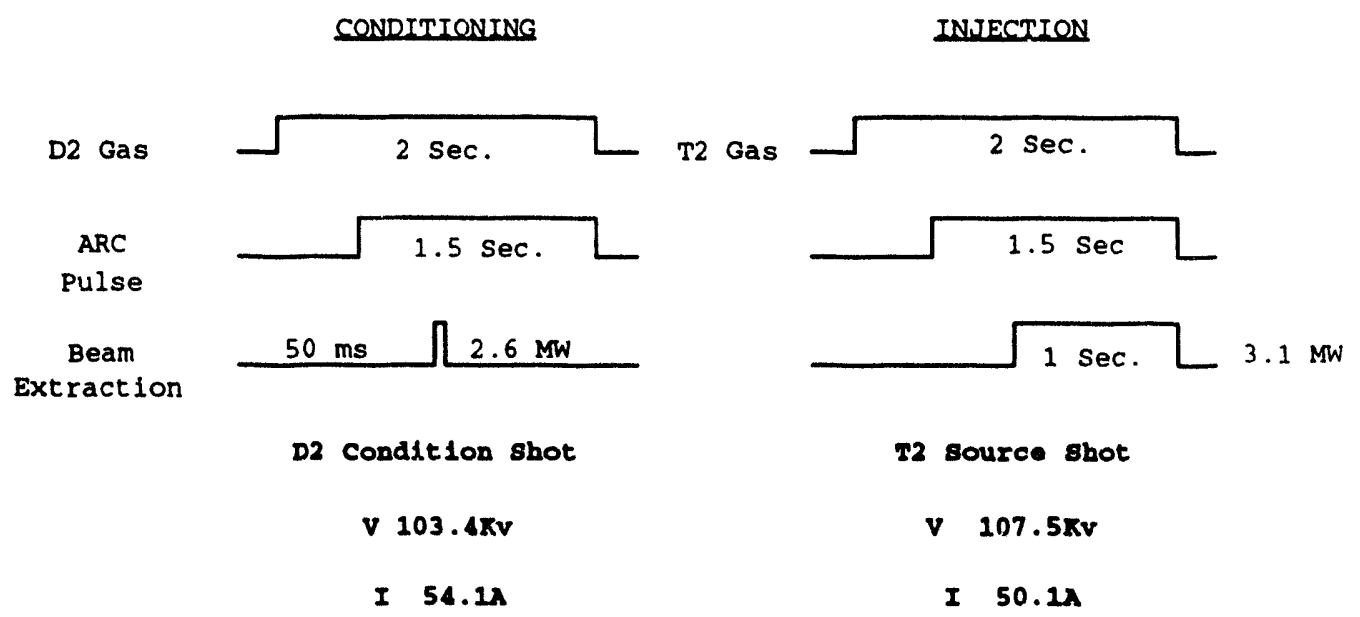

Fig. 2 The beam condition/injection sequence for change over to tritium injection in one step. 


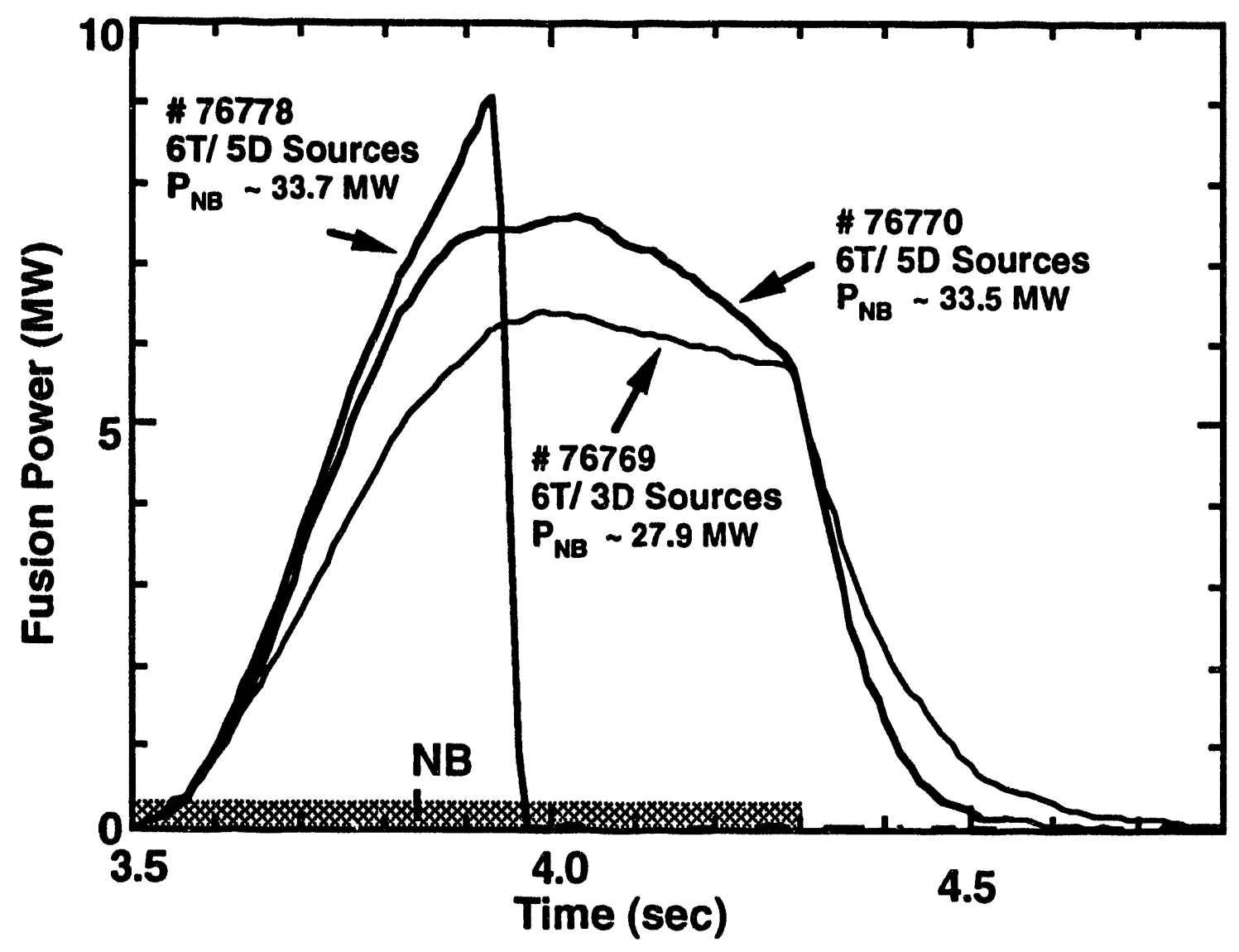

Fig. 3 Fusion power produced with the indicated beam powers and source combinations $\left(\mathrm{I}_{\mathrm{p}}=2.47 \mathrm{MA}, \mathrm{R}=2.52 \mathrm{~m}, \mathrm{a}=0.87 \mathrm{~m}, \mathrm{BT}=5 \mathrm{~T}\right)$. Lithium pellet conditioning was used during these discharges as described in the text.

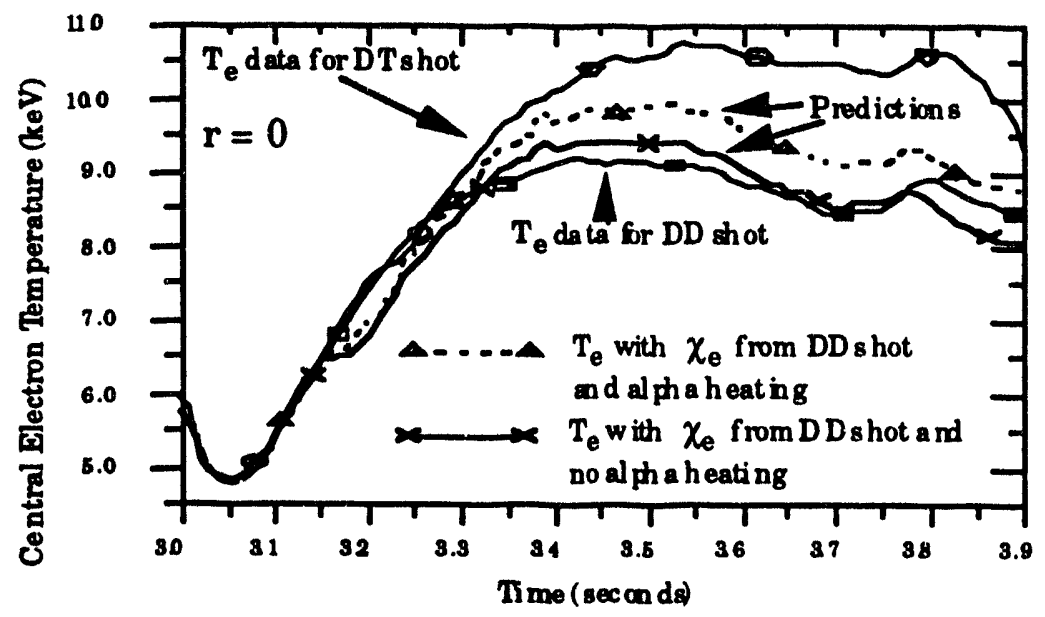

Fig. 4 TRANSP code predictions compared to $T_{e}$ data for DD shot \# 73265 and DT shot \# 73268 or Ref. $6\left(I_{p}=2.0 \mathrm{MA}, \mathrm{R}=2.52 \mathrm{~m}, \mathrm{a}=0.87 \mathrm{~m}, \mathrm{~B}_{\mathrm{T}}=5 \mathrm{~T}, \mathrm{P}_{\mathrm{NB}}=\right.$ 29.5 MW). Predictions for $T_{e}$ with $\chi_{e}$ from the $D D$ shot, with and without alpha heating, are shown. 


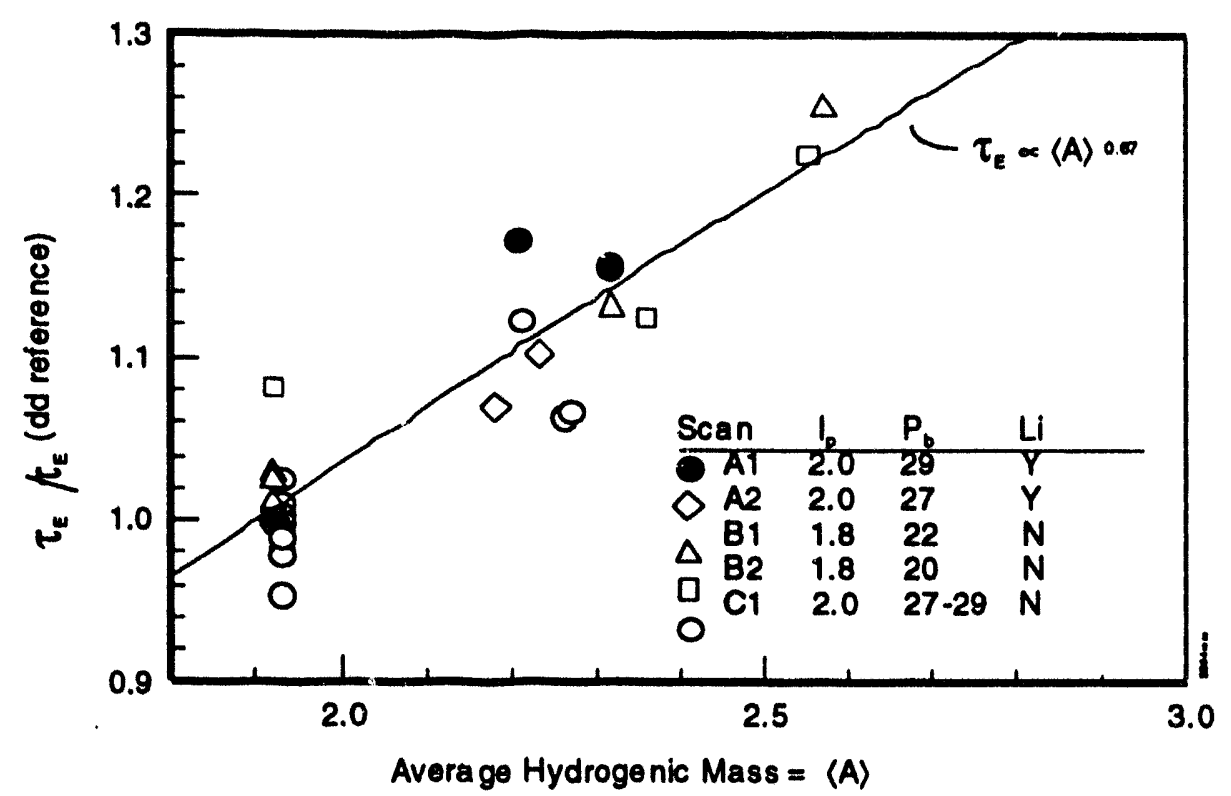

Fig. 5 The ratio of global energy confinement time measured with magnetic diagnostics, $t E=$ WMAG/ (PNB + POH - dWMAG/dt), in similarly prepared plasmas with varying ratios of $D$ versus $T$ beam injection. $t E$ improves as the average hydrogenic ion mass is increased. Lithium pellet injection was used to reduce carbon and hydrogenic influx for scans $\mathrm{A} 1$ and $\mathrm{A} 2$.

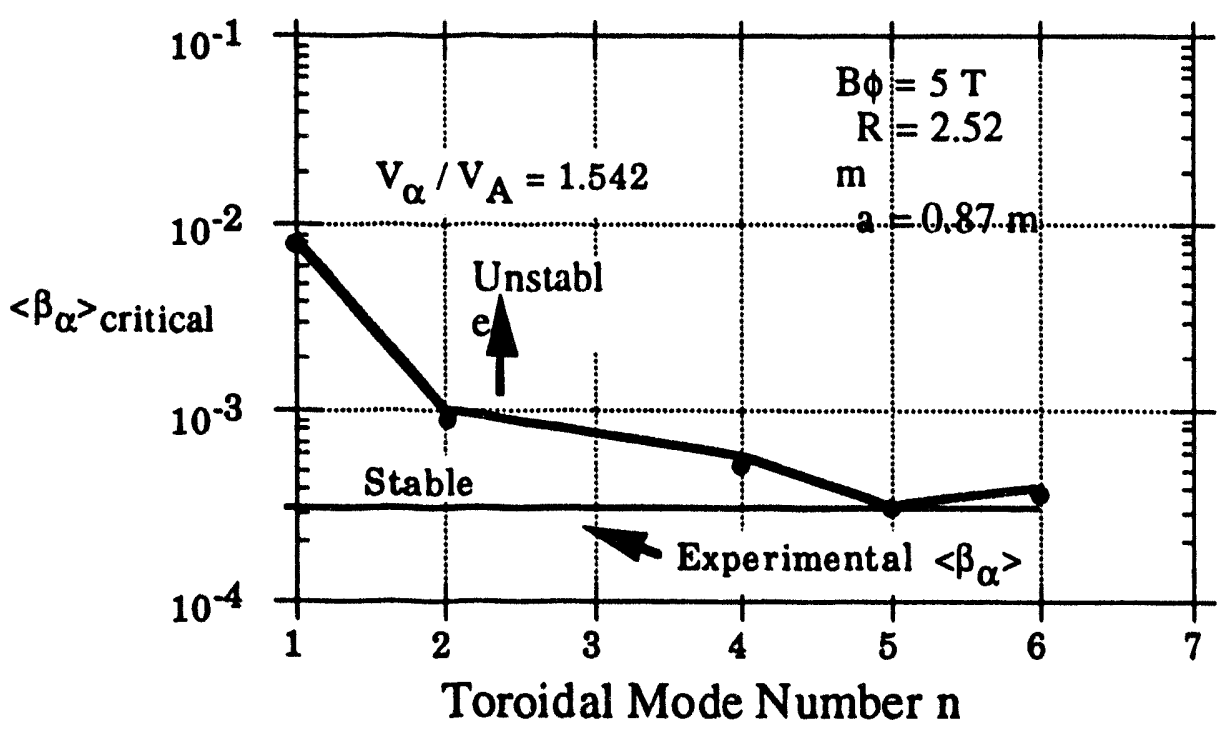

Fig. 6 The theoretical stability boundary for alpha driven TAE modes as a function of toroidal mode number. This prediction is based on supershot profiles corresponding to the conditions for the $6.2 \mathrm{MW}$ shot (\# 73268) of Ref. 6 for which the experimental $\left\langle\beta_{\alpha}\right\rangle$ is indicated. 


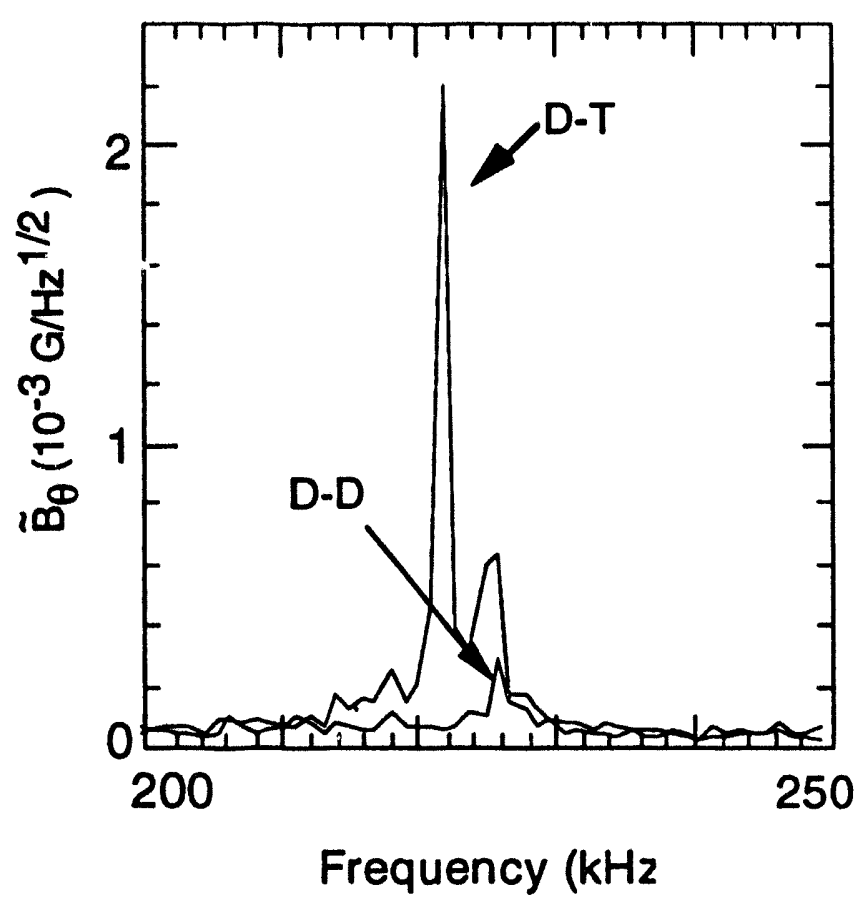

Fig. 7 ICRF heating enhancement of the TAE mode in D-T plasma versus a comparable D-D plasma. $P_{R F}=5.2 \mathrm{MW}$ and $\mathrm{P}_{\mathrm{NB}}=20 \mathrm{MW}$ with 5T/2D sources for $\mathrm{D}-\mathrm{T}$ case and $8 \mathrm{D}$ sources for $\mathrm{D}-\mathrm{D}$ case. $\left(\mathrm{I}_{\mathrm{p}}=1.8 \mathrm{MA}, \mathrm{R}=2.62 \mathrm{~m}, \mathrm{a}=0.97 \mathrm{~m}, \mathrm{BT}=\right.$ $4.8 \mathrm{~T}$ ).

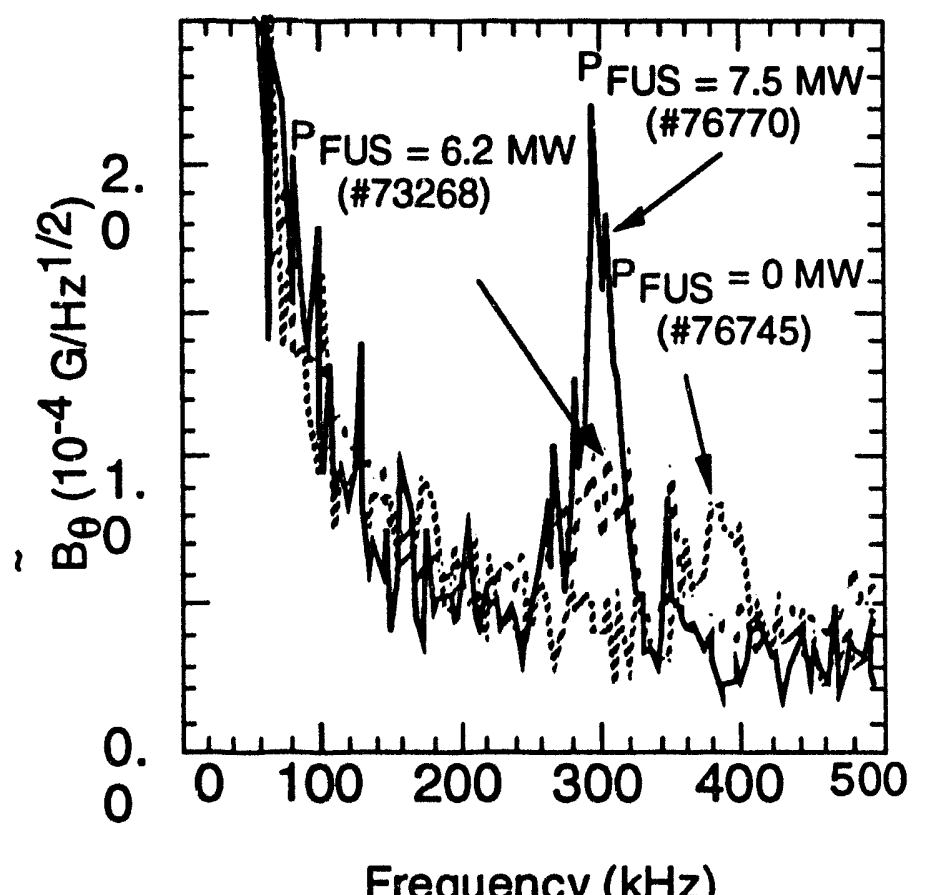

Fig. 8 The enhancement of the TAE-like mode at higher fusion power. Mode levels are compared for PFUS $=7.5 \mathrm{MW}$ (shot \# 76770 of Fig. 3 with PNB $~ 33.5 \mathrm{MW}$ and $6 \mathrm{~T} / 5 \mathrm{D}$ sources), PFUS $=6.2 \mathrm{MW}$ (\# 73268 of Ref. 6 with PNB $\sim 29.5 \mathrm{MW}$ and 7 T/4D sources) and PFUS $\sim 0 \mathrm{MW}$ (\# 76745 with PNB $=28 \mathrm{MW}$ and $10 \mathrm{D}$ sources). 


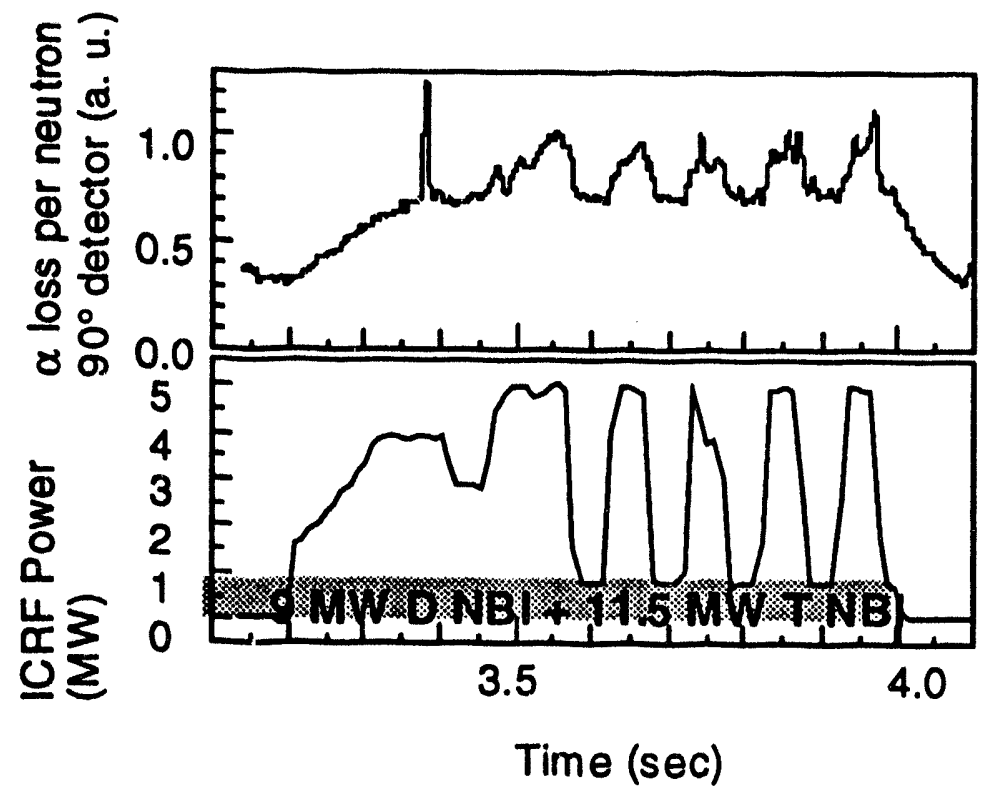

Fig. 9 ICRF heating enhancement of alpha particle loss as measured on the $90^{\circ}$ (bottom of plasma) scintillation detector (Shot \# 74477, BT $=4.4 \mathrm{~T}, \mathrm{I}_{\mathrm{p}}=1.75 \mathrm{MA}, \mathrm{R}=$ $2.62 \mathrm{~m}, \mathrm{a}=0.97 \mathrm{~m}$ ). The doppler broadened $2 \Omega \alpha$ resonance is in the outer part of the plasma where a small addition of $v \perp$ deconfines alpha particles.

Fig. 10

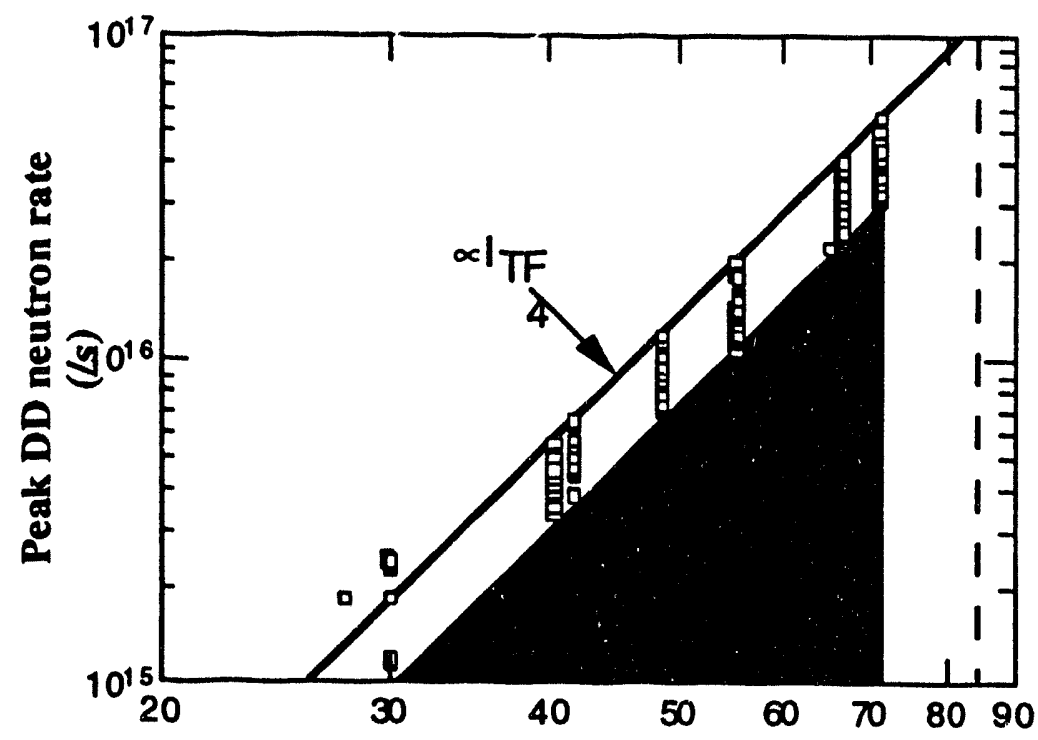

Dependence of the peak DD neutron rate on the toroidal field current for the complete deuterium supershot database. Only the top $10 \%$ of shots [defined with $\left.\mathrm{S}_{\mathrm{n}}(/ \mathrm{s})>1.3 \times 10^{9} \mathrm{I}{ }^{4} \mathrm{TF}(\mathrm{kA})\right]$ are plotted and the remainder of the shots lie in the shaded area. 
Dr. F. Paoloni, Univ. of Wollongong. AUSTRALIA

Prot. R.C. Cross, Univ. of Sydney, AUSTRALIA

Plasma Posearch Lab., Australian Nat. Univ., AUSTRALIA

Prof. I.R. Jones, Flinders Univ, AUSTRALIA

Prot. F. Cap, Inst. for Theoretical Physics, AUSTRIA

Prot. M. Heindler, Institut fur Theoretische Physik, AUSTRIA

Prof. M. Goossens, Astronomisch Instituut, BELGIUM

Ecole Royale Militaire, Lab. de Phy. Plasmas, BELGIUM

Commission-European, DG. XII-Fusion Prog., BELGIUM

Prof. R. Bouciqué, Rijksuniversiteit Gent, BELGIUM

Dr. P.H. Sakanaka, Instituto Fisica, BRAZIL

Prof. Dr. I.C. Nascimento, Instituto Fisica, Sao Paulo, BRAZIL Instituto Nacional De Pesquisas Especiais-INPE, BRAZIL

Documents Office, Atomic Energy of Canada Lid., CANADA

Ms. M. Morin, CCFWTokamak de Varennes, CANADA

Dr. M.P. Bechynski, MPB Technologies, Inc., CANADA

Dr. H.M. Skarsgard, Univ. of Saskatchewan, CANADA

Prof. J. Toichmann, Univ. of Montreal, CANADA

Prof. S.R. Sreenivasan, Univ. of Calgary, CANADA

Prof. T.W. Johnston, INRS-Energie, CANADA

Dr. R. Bolton, Centre canadien de fusion magnétique, CANADA

Dr. C.R. James, Univ. of Alberta, CANADA

Dr. P. Lukác, Komenského Universzita, CZECHO-SLOVAKIA

The Librarian, Culham Laboratory, ENGLAND

Library, R61, Rutherford Appleton Laboratory, ENGLAND

Mrs. S.A. Hutchinson, JET Library, ENGLAND

Dr. S.C. Sharma, Univ. of South Pacific, FIJI ISLANDS

P. Măhönen, Univ. of Helsinki, FINLAND

Prof. M.N. Bussac, Ecole Polytechnique,, FRANCE

C. Mouttet, Lab. de Physique des Milieux lonisés, FRANCE

J. Radet, CEN/CADARACHE - Bat 506, FRANCE

Prof. E. Economou, Univ. of Crete, GREECE

Ms. C. Rinni, Univ. of loannina, GREECE

Preprint Library, Hungarian Academy of Sci., HUNGARY

Dr. B. DasGupta, Saha Inst. of Nuclear Physics, INDIA

Dr. P. Kaw, Inst. for Plasma Research, INDIA

Dr. P. Rosenau, Israel inst. of Technology, ISRAEL

Librarian, Intermational Conter for Theo Physics, ITALY

Miss C. De Palo, Associazione EURATOM-ENEA , ITALY

Dr. G. Crosso, Istituto di Fisica del Plasma, ITALY

Prof. G. Rostangni, Istituto Gas Ionizzati Del Cnr, ITALY
Dr. H. Yamato, Toshiba Res \& Devel Center, JAPAN

Prof. I. Kawakami, Hiroshima Univ., JAPAN

Prof. K. Nishikawa, Hiroshima Univ., JAPAN

Librarian, Naka Fusion Research Establishment, JAERI, JAPAN

Director, Japan Atomic Energy Research Inst., JAPAN

Prof. S. Itoh, Kyushu Univ., JAPAN

Research Into. Ctr., National Instit. for Fusion Science, JAPAN

Prot. S. Tanaka, Kyoto Univ., JAPAN

Library, Kyoto Univ., JAPAN

Prof. N. Inove, Univ. of Tokyo, JAPAN

Secretary, Plasma Section, Electrotechnical Lab., JAPAN

Dr. O. Mitarai, Kumamoto Inst. of Technology, JAPAN

Dr. G.S. Lee, Korea Basic Sci. Ctr., KOREA

J. Hyeon-Sook, Korea Atomic Energy Research Inst., KOREA

D.I. Choi, The Korea Adv. Inst. of Sci. \& Tech., KOREA

Prof. B.S. Liley, Univ. of Waikato, NEW ZEALAND

Inst of Physics, Chinese Acad Sci PEOPLE'S REP. OF CHINA

Library, Inst. of Plasma Physics, PEOPLE'S REP. OF CHINA

Tsinghua Univ. Library, PEOPLE'S REPUBLIC OF CHINA

Z. Li, S.W. Inst Physics, PEOPLE'S REPUBLIC OF CHINA

Prof. J.A.C. Cabral, Instituto Superior Tecnico, PORTUGAL

Prof. M.A. Hellberg, Univ. of Natal, S. AFRICA

Prof. D.E. Kim, Pohang Inst. of Sci. \& Tech., SO. KOREA

Prof. C.I.E.M.A.T, Fusion Division Library, SPAIN

Dr. L. Stenflo, Univ. of UMEA, SWEDEN

Library, Royal Inst. of Technology, SWEDEN

Prof. H. Wilhelmson, Chalmers Univ. of Tech., SWEDEN

Centre Phys. Des Plasmas, Ecole Polytech, SWITZERLAND

Bibliotheek, Inst. Voor Plasma-Fysica, THE NETHERLANDS

Asst. Prof. Dr. S. Cakir, Middle East Toch. Univ., TURKEY

Dr. V.A. Glukhikh,Sci. Res. Inst. Electrophys.I Apparatus, USSR

Dr. D.D. Ryutov, Siberian Branch of Academy of Sa., USSR

Dr. G.A. Eliseev, I.V. Kurchatov Inst., USSR

Librarian, The Ukr.SSR Academy of Sciences, USSR

Dr. L.M. Kovrizhnykh, Inst. of General Physics, USSR

Kemiorschungsanlage GmbH, Zentralbibliothek, W. GERMANY

Bibliothek, Inst. Fur. Plasmaforschung, W. GERMANY

Prof. K. Schindier, Ruhr-Universitát Bochum, W. GERMANY

Dr. F. Wagner, (ASDEX), Max-Planck-Institut, W. GERMANY

Librarian, Max-Planck-Institut, W. GERMANY 

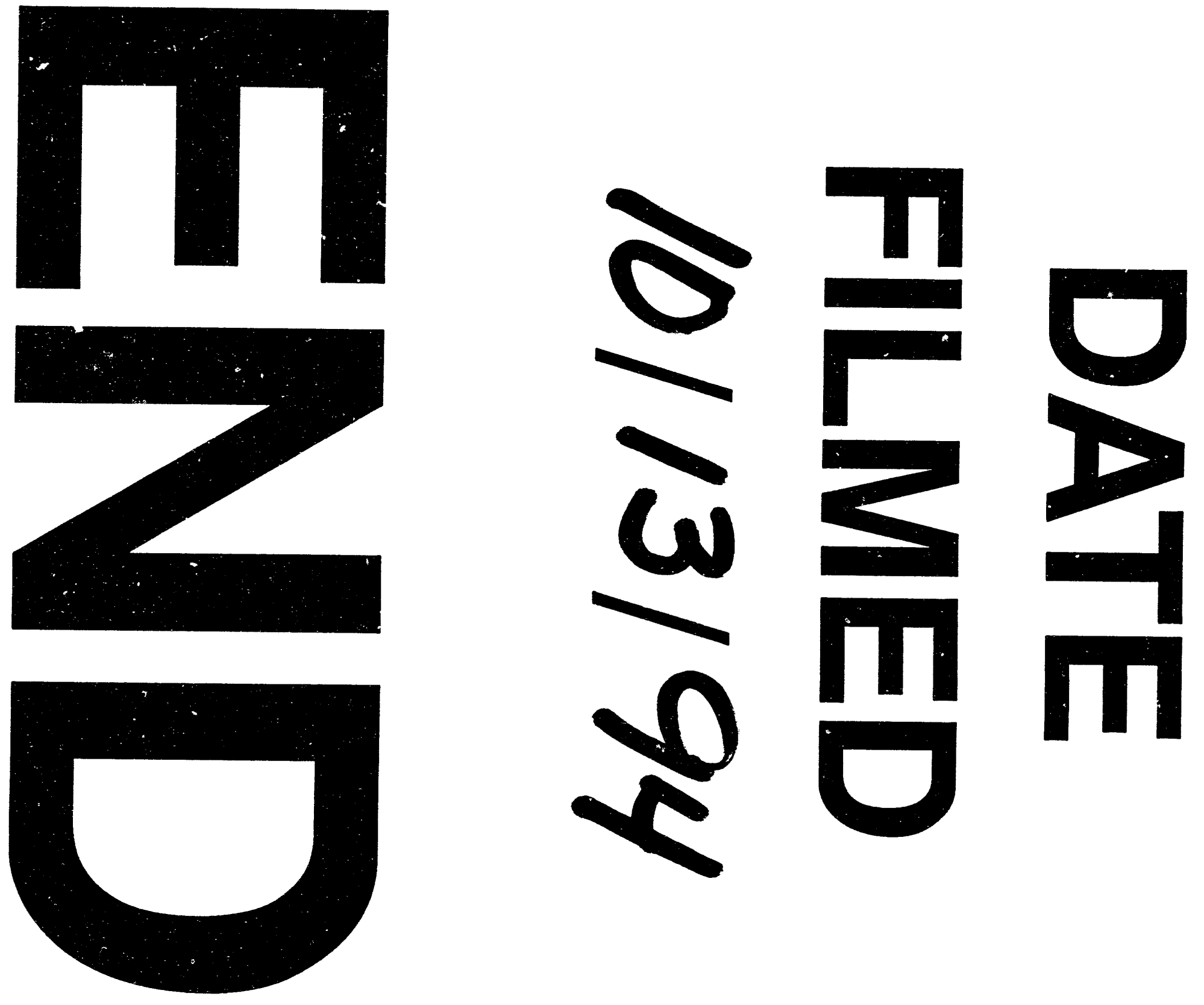
